\title{
SADDLE-NODE BIFURCATION IN THE DYNAMIC ANALYSIS OF A NATIONAL ENERGY MARKET
}

Johan Manuel Redondo

PhD. Professor.

Catholic University of Colombia. Bogota D.C - Colombia

jmredondo@ucatolica.edu.co

Gerard Olivar Tost

PhD. Professor.

National University of Colombia. Manizales - Colombia

golivart@unal.edu.co

Johnny Valencia Calvo

PhD. Professor.

Technological of Antioquia. Medellin - Colombia

johnny.valencia@tdea.edu.co

Danny Ibarra-Vega

PhD. Professor.

National University of Colombia. Manizales - Colombia

dwibarrav@unal.edu.co

Carlos Peña-Rincon

PhD. Professor.

Sergio Arboleda University - Bogotá D.C - Colombia

carlos.pena@usergioarboleda.edu.co

\section{ABSTRACT.}

This article presents preliminary results of the mathematical analysis of a national energy market. The modeling of the studied system was made from causal relationships between the supply and demand of a national energy market, obtaining a system of ordinary differential equations of the first order of the electric power capacity in construction, the electric power capacity installed and the price of electricity in the market (Redondo et.al, 2018). In the dynamic analysis of the model, a saddle-node bifurcation was identified for the case in which the elasticity of the price with respect to the reserve margin 


\section{silem}

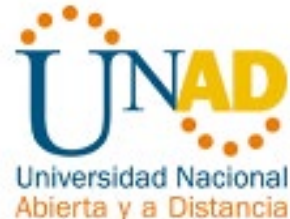

is considered null, which allowed establishing two prospective scenarios of the system: absolute disappearance of the supply of electricity or tendency of growth of the supply to the attention of the demand of the market

\section{Keywords}

National energy markets; equilibria point; saddle-node bifurcation;

Dynamical Systems.

The national energy market is one of the main issues of economic activity in any country. To study its behavior, some models have been constructed that link the most important variables of these markets. The Ceiba Center and the National University of Colombia, have been using the Systems Dynamics methodology with conclusive results for the formation of a regional market (Ochoa, 2010). Different approaches can be used to establish a model of electricity markets, to illustrate, consider the price of electricity. Authors have used statistical techniques (Angelus, 2001, Deng, 2000a, Deng, 2000b, Ethier, 1998, Ethier, 1999, Knittel, 2001, Silva, 2001), neural networks (Velasquez, 2001, Pulgarin, 2001, Rabbit, 2005; Ramsay, 1998; Szkuta, 1998), computational intelligence models (Souza, 2002), fuzzy systems (Medeiros, 2003) and recurrent neural networks (Hong, 2001). In this document we analyze a case of the system of equations obtained for the modeling of an electricity market presented by Redondo et.al. (2018).

The main purpose of this article is to show the preliminary results of bifurcations found in the mathematical model of national energy markets proposed by Redondo et.al. (2018), to conclude on its prospective possibilities in practice. 


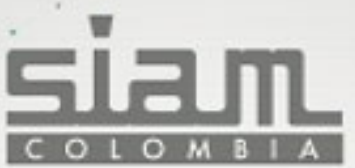

\section{Mathematical model for the energy market}

The mathematical model of the system considers a system of ordinary differential equations of the first order of the electric power capacity in construction $x$, the installed electric power capacity $y$, and the price of electricity in the market $z$ (Redondo et.al, 2018):

Equation 1: Mathematical model of a national energy market.

$$
\begin{gathered}
\dot{x}=\max \left\{0, a\left[1-\frac{c}{p}\left(\frac{y z^{\varepsilon}}{d q}-\frac{1}{q}\right)^{\beta}\right] y\right\}-\frac{x}{k_{1}} \\
\dot{y}=\frac{x}{k_{1}}-\frac{y}{k_{2}} \\
\dot{z}=\frac{1}{k_{3}}\left[p\left(\frac{y z^{\varepsilon}}{d q}-\frac{1}{q}\right)^{\beta}-z\right]
\end{gathered}
$$

where $0 \leq a \leq 1$ is the investment rate in new energy capacity, $c \in \mathbb{R}^{+} \cup\{0\}$ is the unit generation cost, $k_{1} \in \mathbb{R}^{+}$is the construction time, $k_{2} \in \mathbb{R}^{+}$is the average useful life of the generation plants, $k_{3} \in \mathbb{R}^{+}$is the time of adjustment of the real price to the price assumed by the consumer, $p \in \mathbb{R}^{+} \cup\{0\}$ is a reference value of the unit price, $q \in \mathbb{R}$ is a reference value of the reserve margin, $d \in$ $\mathbb{R}^{+} \cup\{0\}$ is a reference value of demand, $\varepsilon \in \mathbb{Q}^{+} \cup\{0\}$ is the elasticity of demand with respect to price and $\beta \in \mathbb{Z}^{+} \cup\{0\}$ is the price elasticity with respect to the reserve margin.

\section{Planar case analysis}

To analyze Equation 1, we can consider different cases associated with the value of the elasticities $\varepsilon$ and $\beta$. For example, if the elasticity of the price with respect to the reserve margin is zero, $\beta=0$, the 3 -dimensional differential system becomes a planar system of the form: 


\section{siam \\ \begin{tabular}{llllllll}
\hline$C$ & $O$ & $L$ & $O$ & $M$ & $B$ & I & $A$ \\
\hline
\end{tabular}}

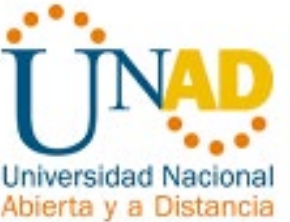

Equation 2: Simplification of the differential system of Equation 1 for the case in which the elasticities are zero

$$
\begin{gathered}
\dot{x}=\max \left\{0, a\left(1-\frac{c}{p}\right) y\right\}-\frac{x}{k_{1}} \\
\dot{y}=\frac{x}{k_{1}}-\frac{y}{k_{2}}
\end{gathered}
$$

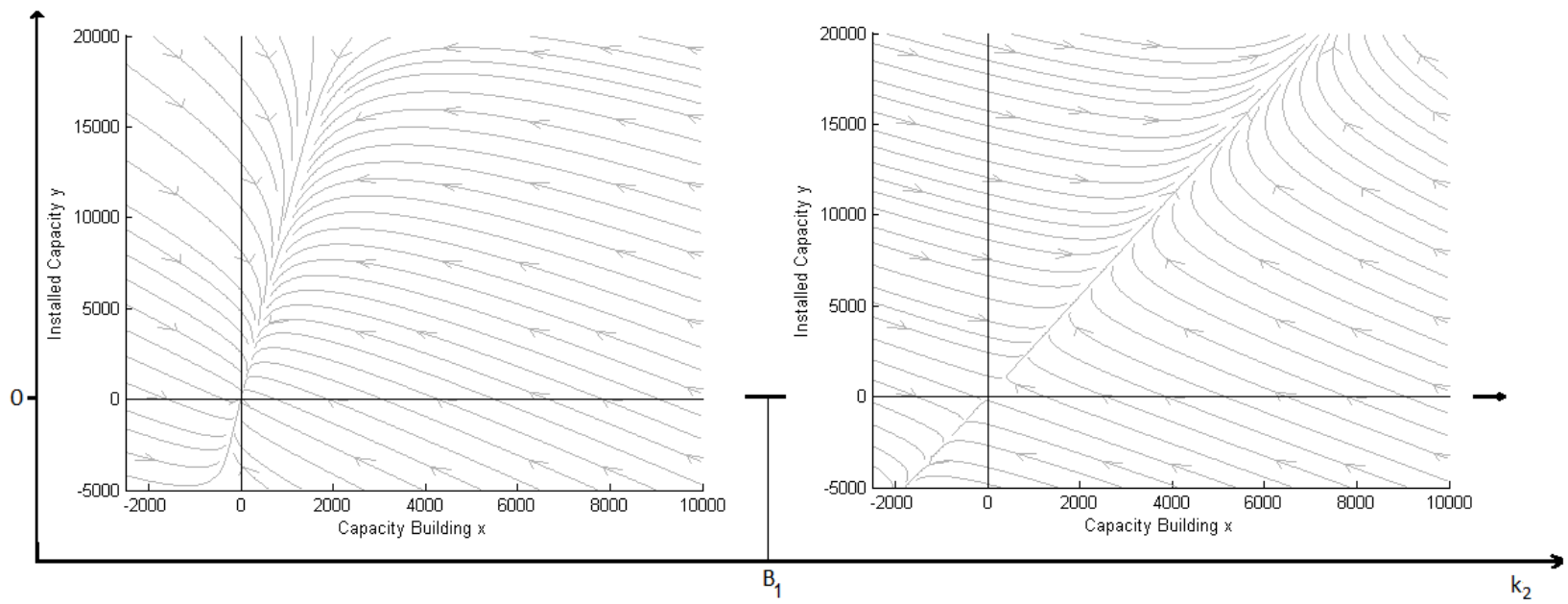

Figure 1: Bifurcation saddle-node under the parameter $k_{2}$ for the case where the elasticities are null and the maximum in Equation $\mathbf{2}$ is not zero.

For this system we have the following proposition.

Proposition 1: When the maximum in Equation 2 is zero, the system has a stable equilibrium point at the origin. When the maximum is not zero, that is, the reference value of the unit price is greater than the unit generation cost: $p>c$, the origin has a saddle-node bifurcation in $k_{2}=B_{1}$, with $B_{1}=p /(a(p-$ $c)$ ). If $k_{2}<B_{1}$, the origin is stable. If $k_{2}>B_{1}$, the origin is a saddle node.

Figure 1 shows the simulation of the system showing the sadle-node bifurcation that occurs due to the variation of the parameter time of 


\section{Sijemt}

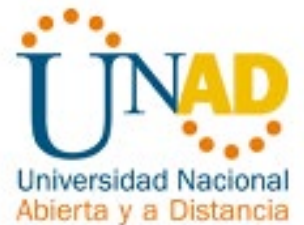

adjustment of the real price to the price assumed by the consumer $k_{2}$ under conditions of price elasticity with respect to the margin of zero reserve and price unit greater than the cost of unit generation: $p>c$.

Other cases from the elasticities can be considered for the bifurcation analysis of Equation 1. However, in the context of this paper the discussion of this found bifurcation case is intended.

\section{Conclusions}

The hypothetical case presented, in which the elasticity of the price with respect to the reserve margin is null, is the case in which the market does not react to the variations in the supply and demand relationship, which can occur when there is a regulation that fixes the price, considered here the reference value $p$ or when the substitute in the market can supply in the same conditions the demand of the users.

Clearly it is an ideal case that has more theoretical than practical character, however, it is identified that the realization of investments, given by the positive maximum in Equation 2, is not enough to guarantee the supply of

electricity to the national market. The system must maintain the adequate and non-trivial relationship between the reference price and generation costs in order to maintain supply growth proportional to the growth in demand.

This is the case in which the investment must reach a non-zero minimum to be viable for the system. This viable minimum was identified in the system as the bifurcation value $B_{1}$, for the special case studied. 


\section{REFERENCES}

- Redondo, J.M., Olivar, G., Ibarra-Vega, D. and Dyner, I. (2018). Modeling for the regional integration of electricity markets. Journal Energy for Sustainable Development, volume 43, pages 110-113, Elsevier. https://doi.org/10.1016/j.esd.2017.12.003.

- Ochoa, M.C. (2010). Análisis de la integración eléctrica Panamá CAN bajo el esquema de subasta implícita. Tesis de grado para optar al título de magíster en ingeniería de sistemas, director: Carlos Jaime Franco C., PhD, Facultad de Minas Universidad Nacional de Colombia, sede Medellín. http://www.bdigital.unal.edu.co/2531/1/43221793.2010.pdf

- Angelus, A. (2001). Electricity price forecasting in deregulated markets, The Electricity Journal.

- Deng, S. (2000a), Princing electricity derivatives under alternative stochastic spot price models, in Preceedings of the 33rd Hawaii International Conference on System Sciences.

- Deng, S. (2000b), Stochastic models of energy commodity prices and their applications: Mean reversion with jumps and spikes, Technical report, Program onWorkable Energy Regulation (POWER) working paper 073.

- Ethier, R. y Mount, T. (1998), Estimating the volatility of spot prices in restructured electricitymarkets and the implications for options values, Technical report, Cornell University.

- Ethier, R. (1999), Valuing electricity assets in deregulated markets: A real options model with mean reverting and jumps, Technical report, Cornell University. 


\section{รìmน}

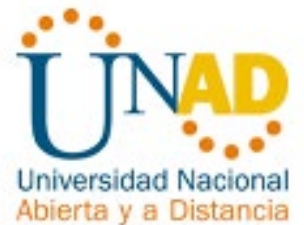

- Knittel, C. y Roberts, M. (2001), An empirical examination of derregulated electricity prices, Technical report, Program on Workable Energy Regulation (POWER) University of California, Energy Institute.

- Silva, B., Teixeria, J. y Gomes, L. (2001), Previsao de precos spot e avaliacao de projetos de geracao termeletrica, in IX Semiario de Planejamento Economico Financeiro do Setor Eletrico (SEPEF).

- Velásquez, J. D. y Dyner, I. (2001), Pronóstico de precios de bolsa de electricidad usando un modelo de redes neuronales artificiales, in EITI2001, Universidad Nacional de Colombia.

- Pulgarín, A., Smith, R. y Poveda, G. (2001), Predicción del precio de la energía eléctrica con un modelo de redes neuronales y usando variables macroclimáticas, in XIV Seminario Nacional

- de Hidráulica e Hidrología, Colombia.

- Conejo, A., Contreras, J., Espinosa, R. y Plazas,M. (2005). Forecasting electricity prices for a day-ahead pool-based electricity energy market, International Journal of Forecasting 21.

- Ramsay, B. y Wang, A. (1998). A neural network based estimator for electricity spotpricing with particular reference to weekend and public holidays, Neurocomputing (23).

- Szkuta, B., Sanabria, L. y Dillon, T. (1998). Electricity price short-term forecasting using artificial neural networks, IEEE Transactions on Power Systems 14(3).

- Souza, R. (2002). Modelling the brazilian spot price series, in IFORS 2002.

- Medeiros, L. (2003). Previsao do Preco Spot no Mercado de Energia Eletrica, PhD thesis, Pontificia Universidade Catolica do Rio de Janeiro.

- Hong, Y. y Hsiao, C. (2001), Locational marginal price forecasting in deregulated electricity markets using a recurrent neural network, in IEEE Power Engineergin Society Winter Meeting. 